Article

\title{
Participatory Infrastructures: The Politics of Mobility Platforms
}

\author{
Peter T. Dunn \\ Department of Urban Design and Planning, University of Washington, Seattle, WA 98195, USA; E-Mail: ptdunn@uw.edu
}

Submitted: 15 July 2020 | Accepted: 28 August 2020 | Published: 15 December 2020

\begin{abstract}
Much of everyday life in cities is now mediated by digital platforms, a mode of organization in which control is both distributed widely among participants and sharply delimited by the platform's constraints. This article uses examples of smartphone-based platforms for urban mobility to argue that platforms create new political arrangements of the city, intermediating the social processes of management and movement that characterize urban life. Its empirical basis is a study of user interfaces, data specifications, and algorithms used in the operation and regulation of ride-hailing services and bike-share systems. I focus on three aspects of urban politics affected by platforms: its location, its participants, and the types of conflict it addresses. First, the programming forums in which decisions are encoded in and distributed through platforms' core digital architecture are new sites of policy deliberation outside the more familiar arenas of city politics. Second, travelers have new opportunities to use platforms for travel on their own terms, but this expanded participation is circumscribed by interfaces that presuppose individual, transactional engagement rather than a participation attentive to a broader social and environmental context. Finally, digital systems show themselves to be well suited to enforcing quantifiable distributional goals, but struggle to resolve the more nuanced relational matters that constitute the politics of everyday city life. These illustrations suggest that digital tools for managing transportation are not only political products, but also reset the stage on which urban encounters play out.
\end{abstract}

\section{Keywords}

digital geographies; infrastructure; participation; platform urbanism; shared-use mobility

\section{Issue}

This article is part of the issue "Digital Geographies and the City" edited by Wen Lin (Newcastle University, UK).

(C) 2020 by the author; licensee Cogitatio (Lisbon, Portugal). This article is licensed under a Creative Commons Attribution 4.0 International License (CC BY).

\section{Introduction}

In recent years, a smartphone in your pocket has for many become every bit as indispensable for getting around the city as car keys or a transit pass. Mobile apps provide information on the fastest driving routes through current traffic or the estimated arrival time of the next bus. They hail drivers of Ubers, and they unlock shared bicycles and scooters. Behind much of this new digital mediation of urban mobility is the platform, an arrangement that both facilitates and bounds social interaction. Digital platforms, fueled by big data and accelerated by the automatic operations of algorithms, have come to dominate the Internet (Helmond, 2015). With the proliferation of 'sharing economy' platforms like Uber and Airbnb, the platform's reach has become apparent beyond the computer screen and in the city, a move charted by the emerging literature on 'platform urbanism' (Barns, 2020; Leszczynski, 2019a; Rodgers \& Moore, 2018). While these platforms have clearly become more present in our everyday lives online and in the city, what is sometimes less apparent is what they do differently than the systems they supplant. Is Uber simply a more convenient taxi? Or does it represent a qualitative transformation in how we engage with the city?

This article answers by examining the political dimensions of platform interventions in urban mobility. It uses two inherent and seemingly contradictory qualities of the platform-the centralized control exerted by its core structure and its openness to modification by its participants-to argue that mobility platforms are not neutral technical solutions applied to simple transportation problems, but are instead active players in shaping the engagements of urban inhabitants with 
each other and their city. The platforms, in short, are political (Andersson Schwarz, 2017; Butt, McQuire, \& Papastergiadis, 2016; Plantin, 2015), and the focus here is on politics in a particular sense. Following a generation of scholarship in science and technology studies, recent studies of platforms have looked at the consequences of platform politics - for example, the ways in which "digitality (re)produces power and extant sociospatial inequalities along lines of race, gender, class, sexuality, age, ability and more" (Elwood \& Leszczynski, 2018, p. 630). At the same time, technologies are also products of socially situated human values, an argument at the heart of science and technology studies literature (Bijker, Hughes, \& Pinch, 1987; MacKenzie \& Wajcman, $1985)$ that applies equally to platforms. Work in the political economy vein, for example, has critically examined platforms as tools of value production and accumulation reflecting the capitalist paradigm of their creators (Langley \& Leyshon, 2017; Srnicek, 2017). In this article, however, I position the platform not just as a product or producer of politics, but as the very site in which political engagement happens. Platforms have "politics" in the sense that Chantal Mouffe describes as an "ensemble of practices, discourses and institutions that seek to establish a certain order and to organize human coexistence" (1999, p. 754), a framing of power-laden resolution and exclusion that Crawford (2016) has successfully applied to the workings of software. The participatory nature of platforms, which are extended and modified by actors pursing disparate agendas, highlights this political function in ways that other sociotechnical systems do not. In this light, this article's contribution is to illustrate the politics of platforms by examining the ways that urban mobility platforms establish new arenas of deliberation, specify the kind of participant who is imagined to engage in the platform, and identify the type of disputes that can be resolved.

The empirical demonstration of this digitally mediated politics is a qualitative study of urban mobility platforms focusing on smartphone apps and supporting software for ride-hailing and bike share. The examples are of a data specification, a user interface, and an algorithmic approach to policy enforcement. Each of these three addresses a familiar concern for municipal regulators: traveler privacy, the use of single-occupancy vehicles, and bicycle parking in the public right-of-way, respectively. The application of platforms to these concerns, however, demonstrates the political dimensions of the platform's intermediation. In these examples, the platform transfers multiple local policy positions into a single standards-based design that then shapes subsequent use indiscriminately. It provides room for participants to exercise their own agency in their travel, but favors a participation that is individualistic and transactional. And it offers algorithmic resolutions to conflicts that are easily monitored and quantified, but struggles to mediate the messy everyday relations of people sharing space in the city. In each of these, the inherent qualities of digital plat- forms, as applied to urban mobility, shape subsequent modes of engagement among people in the city. Before presenting these cases, the following section discusses these qualities in a brief introduction to theorizations of platforms and platform urbanism.

\section{Platforms as Participatory Infrastructures}

The concept of the 'platform' has been used in Internet studies to describe the simultaneous expansion of usergenerated content and concentration of control in a handful of companies. In a paradigmatic example, Facebook is characterized by users freely posting and interacting in ways that Facebook does not direct. At the same time, this participation is structured and monitored by Facebook's technical and institutional architectures, and it generates value that accrues to Facebook the corporation. As a platform, then, Facebook both decentralizes production and centralizes control of Internet content (Helmond, 2015). These seemingly contradictory tendencies, towards heterogeneous and expanded participation on the one hand and standardization and centralized control on the other, is the essential paradox of platforms (Ananny \& Gillespie, 2016; Andersson Schwarz, 2017). Van Dijck, Poell, and de Waal (2018) define a platform as "a programmable digital architecture designed to organize interactions between users" (p. 4), and most definitions share these two essential elements: a core architecture or framework that is built and controlled centrally, and the participation of users in contributing to or interacting within its organization.

No single definition captures the many kinds of systems referred to as platforms in practice, and the term itself slides easily between technical, political, economic, and social definitions (Gillespie, 2010). Online, platforms describe social media, the sharing economy, and online marketplaces. In stricter technical definitions, platforms are not simply tweets or Uber rides, but are characterized by their programmability. Platforms like Microsoft Windows prescribe the software standards by which third parties develop new applications that operate on the platform, extending the platform's utility beyond the designs of its creators (Mackenzie, 2018; Plantin, Lagoze, Edwards, \& Sandvig, 2018). More social perspectives see platforms as modes of interpersonal connectivity and templates for organizational management (Kelkar, 2018; van Dijck et al., 2018), while economic views characterize them as multi-sided markets facilitating connections between buyers and sellers. Their emphases differ, but these perspectives share an attention to platforms' bringing together of technical structures and social exchange.

Cities similarly comprise both built infrastructures and interpersonal relations, and recent work in 'platform urbanism' has articulated analytically fertile resonances between platforms and cities. Geographers have long insisted that the screen-based practices of the Internet are not merely 'virtual' phenomena somehow divorced from physical places, but instead are practices that occur 
in and through already existing social and spatial contexts (Ash, Kitchin, \& Leszczynski, 2018; Graham, 2005; Kitchin \& Dodge, 2011; Thrift \& French, 2002). In this vein, the emerging platform urbanism scholarship has taken theorizations of platforms developed mostly in media studies and drawn out their geographical and urban dimensions. By paying attention to the ways that platforms are actually lived out in everyday practices of, for example, labor (Richardson, 2020) and mobility (van der Graaf \& Ballon, 2019), this work on the "emergent, irreducible, co-generative dynamics between platforms and the urban" (Rodgers \& Moore, 2018) illuminates how the city has become a site for "the re-encoding or remediation of urban socio-spatial relationships into territories for platform intermediation" (Barns, 2019, emphasis in the original). Like platform studies more broadly, the emerging literature on platforms is multifaceted. Here I take two themes of platform urbanism as points of departure: infrastructure and participation.

First, an understanding of platforms requires engagement with theories of material infrastructures and their politics, argue Plantin et al. (2018). Increasingly, they say, digital platforms are taking on qualities of infrastructure by becoming ubiquitous, essential, and takenfor-granted (Star, 1999). At the same time, they see a "platformization of infrastructure" in the ways that public infrastructures like roadways that were once delivered according to an ideal of universal service provision are increasingly managed with differential access according to a neoliberal logic of individualization and profit (Graham \& Marvin, 2001). In cities, the platform operates somewhat differently than infrastructure in that it reorganizes cities "not through new physical infrastructures, but instead through novel technologies of coordination" applied to existing infrastructures (Richardson, 2020, p. 460). The city's transit systems, sewer lines, and parks have been recognized as products of specific social values and power relations that then continue to shape cities through their material endurance (McFarlane \& Rutherford, 2008; Winner, 1980). As city transportation departments who once delivered buses and bike share systems now, in addition or instead, provide transit data and permit third-party shared mobility vendors, platform urbanism offers a path for studying the power of the platform's central architecture through the lens of infrastructural politics.

Second, the platform's emphasis on the participation of its users leads platform urbanism to a focus on the city's people, not just its software systems. Antecedent studies and critiques of the smart city, which generally address large-scale deployments of digital technologies in the monitoring and control of urban systems, often employ a political-economic analytic of capitalism, neoliberalism, or technocracy aimed at the scale of a system or an organization. Leszczynski (2019a) has faulted these accounts for advancing "totalizing" narratives of capitalist domination that occlude any other analytical frames, particularly the actually lived experiences of peo- ple exercising their own agency in and through urban systems (see also Rose, 2017), and she cautions the study of platforms against taking the same path. The potential of platform urbanism, Leszczynski argues, is in offering "a more hopeful platform urban politics by extending and recognizing ordinary urban denizens' abilities to express political capacity through everyday digital interactions and practices" (Leszczynski, 2019a, p. 13). The participation and programmability inherent to platforms mean that we cannot understand a platform by studying only the system structure itself; we must also look to what people actually do with the platform (Fields, Bissell, \& Macrorie, 2020; Leszczynski, 2019b). If, as Sarah Barns says, platforms are "highly participatory ecosystems of interaction" that "engender and reshape everyday selves and spaces in vital ways" $(2019$, p. 2), then the sociality of the city offers critical sites for examining the politics of platform participation.

Before turning to one such site, a final observation concerns the place of platforms in urban planning literature. Planners' attention to platforms to date has seen them primarily as disruptions to established regulatory regimes. Airbnb and Uber, in the most prominent examples, have sidestepped local governments' traditional controls of land use and transportation. Planners, in response, have sought to identify the public interest being served or impeded by these corporate platforms, then devised new regulatory approaches applicable to these technologies that will protect these interests (e.g., Gurran \& Phibbs, 2017; Kim et al., 2019). Broadly speaking, this approach sees platforms as simply a different kind of infrastructure, a system to be managed such that benefits are distributed equitably and negative externalities are minimized. In contrast, the perspectives discussed above emphasize how the participatory qualities of platforms differentiate them from infrastructures, despite similarities in their material power. Rather than being objects of an external political deliberation, platforms are in important ways sites of politics themselves. A provider-regulator framing therefore risks oversimplifying the task of managing platforms by downplaying the ways that their inherent extensibility by users will always frustrate efforts at control, even by their creators. This "slipperiness" (Fields et al., 2020) or "ephemerality" (Graham, 2020) of platforms means that despite the influence of their core structure, there is often no single point of intervention through which to protect any identified public interest. Their political dimensions are therefore more extensive and more complex. The following examples seek to provide a more nuanced understanding of these qualities.

\section{Case Illustrations: App-Based Urban Mobility}

The remainder of this article takes these infrastructural and participatory aspects of platform urbanism as lenses for thinking through the political dimensions of app-based urban mobility. I use three examples of 
mobility platforms-a data specification (the General Bikeshare Feed Specification, henceforth GBFS), a user interface (on Lyft's app for ride-hailing), and algorithmic tools for monitoring and enforcing regulatory compliance (for parking of Lime's shared bikes and scooters). Platforms are characterized in part by their capacity to bring together different categories of participants pursing different types of goals. Each of the following cases was therefore selected for its illustration of a particular kind of mobility platform actor: the software developer shipping a product, the end-user making a trip, and the vendor ensuring regulatory compliance, respectively. Furthermore, these three examples demonstrate how platform qualities appear at different technical and political scales. The organizations and software in these examples have international scope, but my investigation frequently grounds them in the specific experiences of a single city, Seattle. This city is used primarily to illustrate the interactions of platforms with a given regulatory environment, and so the particular demographic characteristics of the city are not directly relevant to the discussion.

The cases presented emerged from a larger research project investigating the nature of the public produced by digitally mediated urban mobility. Data was collected with a variety of qualitative methods. First, I reviewed public documents and testimony surrounding the City of Seattle's permitting of free-floating bike share vendors. In the summer of 2017, Seattle became the first North American city to host such a 'dockless' bike-share system. In August of 2018, at the completion of its initial oneyear pilot, the city developed a new permitting structure (Seattle Department of Transportation, 2018), a process paralleling that of many other cities creating comparable regulations at the same time. The public discussions about the appropriate place for this emerging form of mobility in Seattle generated fruitful data on the policy response to a new and largely untested mobility platform.

I supplemented this Seattle perspective with attendance at two national industry conferences and by monitoring vendor news related to ride-hailing and free-floating bike and scooter share systems. Additionally, I followed the development of two opensource software projects related to mobility data, the Mobility Data Specification (MDS) and GBFS, on GitHub, a popular code repository. Their histories differ, but each is in a relatively early stage of development that is wellsuited to an analysis of the process by which values and politics become incorporated into software. With this data from conferences, industry news, and code, I was specifically attentive to the ways that technical capacities of these systems shape the means by which various actors negotiate their intersecting agendas.

Finally, insight into the user experience of platformmediated urban mobility was provided by 18 semistructured interviews and three focus groups with Seattle-based end-users of mobility apps. To contrast different types of users, subjects were selected from two populations: young tech-savvy professionals and the res- idents of independent-living senior centers. In these discussions, I asked subjects how apps for hailing rides or accessing shared vehicles either restricted or expanded their abilities to meet their mobility needs.

There are limitations to the generalizability of these cases, which are products of their particular circumstances, and the specific politics of platforms will surely vary with different technical infrastructures or different participants. Still, these examples are instances of patterns that are expected to repeat, with variations, across other mobility platforms and in other places. In particular, the paradoxical coexistence of participation that is both restricted and expanded, an idea emerging from media studies research discussed above, is persistent across these examples. These cases illustrate this general tendency without claiming to represent the precise ways the politics will play out elsewhere. Ongoing scholarship in platform urbanism suggests that there is much work to be done to continue to trace the contours of these phenomena across cultural and technical contexts.

\subsection{Infrastructure: Data Specifications as a Political Site}

Data specifications, which govern the exchange of information over application programming interfaces (APIs) by defining a standard format for digital information, are at the core of platform architecture. Standards are of course not unique to APIs or platforms, and have been shown in many other contexts to exert power over behavior and relations (Busch, 2011; Galloway, 2004). Within platforms, APIs are the means by which heterogeneous external elements are brought into the scope of control of the platform (Bucher, 2013; Helmond, 2015). In the field of urban mobility, a handful of key data specifications underlie the APIs through which mobility service providers, municipalities, and users communicate. This illustration focuses on one such specification, GBFS.

Like most cities with bike sharing systems, the Seattle Department of Transportation (2018) requires bike share operators to produce APIs conforming to GBFS. This standard specifies, through a set of JSON schema, how the location of bikes currently available to rent is communicated from mobility vendors to third-party apps. Travelers using these apps can then find the nearest available bike at the moment. Seattle also requires data using a related standard, MDS, which provides a historical view of trips, including origins, destinations, and routes, within a given time frame to aid transportation officials in monitoring vendor performance and planning infrastructure improvements. While GBFS data is publicly available and is ultimately intended for use by travelers, MDS data is available only to regulators, in part because it contains sensitive information about individual trips.

Both specifications have developed as open-source projects with all code and documentation publicly available on GitHub (North American Bikeshare Association, 2020; Open Mobility Foundation, 2020). Besides being transparent, these projects are also ostensibly open to 
contributions from anyone. While the open-source software movement reflects a belief in the benefits of more accessible and egalitarian participation in software development, research into these communities over the past two decades has shown how the persistence of social and technical barriers to joining (Steinmacher, Graciotto Silva, Gerosa, \& Redmiles, 2015; von Krogh, Spaeth, \& Lakhani, 2003) and contributing to (Ducheneaut, 2005; Nafus, 2011) such projects undermines any notion that they exist outside of preexisting social disparities. Both the GBFS and MDS projects state an expectation that their contributions will come primarily from a particular community-representatives of affected government agencies, mobility vendors, or third-party software providers. Each project has a few dozen listed contributors, a small portion of whom drive most of the discussion and development. Confirming previous studies of opensource software development, there are clear dimensions of deliberation and exclusion within these communities. The following example further illustrates how the development of the platform's core has implications for subsequent implementation by platform participants.

In the spring of 2019, a GBFS contributor raised a concern on GitHub that bike_id, a GBFS data field uniquely identifying the bicycle, could be used to reconstruct a trip if the ID is stable (North American Bikeshare Association, 2019b). By scraping data from this public feed, a nefarious actor could use bike_id to follow the location of a given bicycle, compromising the privacy of individual riders' origins and destinations. Other contributors generally agreed that this vulnerability should be fixed, and proposed a variety of technical changes to the specification to do so. Suggestions included securing bike_id with authentication, including it only in a separate authenticated feed, requiring vendors to change bike_id after every trip, and dropping it from the spec entirely. In discussing the merits of these options, in online discussion boards on GitHub (North American Bikeshare Association, 2019b, 2019c) over nine months and at a September 2019 conference workshop (North American Bikeshare Association, 2019a), the developer community revealed tensions in use cases and implementation of the specification.

For the end user, a public bike_id allows travelers to find and reserve a bike through a mobile app. In this use case, there is no need to know anything about the past locations of a given bike. However, bike share vendors and municipal regulators have also used bike_id for other purposes, such as monitoring fleet utilization or identifying 'stale' bikes parked too long in one place. For these uses, a stable bike_id is helpful. Resolving the privacy vulnerability created by a stable bike_id therefore also required clarifying the purpose of the specification itself. Among the "guiding principles" of GBFS is that it is "targeted at providing transit information to the bikeshare end user....GBFS is about public information" (North American Bikeshare Association, 2020). One contributor recognized that some cities had been using bike_id to track vendor compliance, but echoed this guiding principle in arguing that "GBFS is intended to be used for traveler-facing information...going forward privacy concerns outweigh alternate use cases like this for GBFS that fall outside its primary purpose." Ultimately, the accepted solution was grounded in these guidelines favoring the traveler, and this resolution suggested that MDS, which is specifically targeted at municipal users, could better support the other use cases.

$A$ related issue in updating the specification concerned the ease of implementation of any proposed change. Since GBFS is already in wide use, any change to the spec that is incompatible with previous versions could require a significant investment of resources to implement across many producers and consumers of this data. A representative of Google Maps, for example, explained that their integration with one vendor, which allows users to reserve the vendor's bikes through Google's app, depends on a stable bike_id. Meanwhile, other mobility vendors said that they were already changing bike_ids in their data feeds, thus avoiding the originally flagged privacy vulnerability and minimizing the impact of requiring these ID changes.

In January 2020, a vote was held among GBFS contributors on GitHub to approve a proposed change to the specification requiring vendors to change each bike's bike_id to a new, random ID at the end of each trip. Seven contributors, representing both producers and consumers of GBFS data, voted in favor, and none against. The change has now been implemented in the latest version of the spec.

Kate Crawford (2016), in arguing that algorithms have politics, has pointed out that what appears to be the deterministic outcome of a computational process is better described as the superficial resolution of a stillpresent but obscured conflict. Here too, a technical fix has been implemented, but the alternatives, which might have better served certain users, simply disappear. Compromise and exclusion are in the nature of standards, and any software development must balance competing objectives. The city of Seattle has been proactive in defining its policies for protecting traveler privacy, including city data collection and handling (Seattle Department of Transportation, 2019), yet it has no direct control over the GBFS standard and its resulting privacy implications. Although consumers of GBFS can disagree about the relative merits of, say, traveler privacy and ease of data analysis for their given situation, the standardization requirements of the platform sharply limits their ability to engage on their own terms (Butt et al., 2016). Instead, deliberations and prioritizations that play out in software development forums propagate constraints across users universally.

\subsection{Participation: Use Mediated by Interfaces}

The discussion of data specifications has already hinted at limitations in platform participation. Despite being an 
open-source project, contribution to GBFS is largely limited to those with a baseline of technical knowledge and a professional affiliation with a mobility service. Here, however, I focus on participation not in platform production, but in the broader sense of the platform's use. This participation, as in tweets and 'likes,' is the basis of the empowering 'connectedness' celebrated by platform proponents, but its power is regularly criticized as superficial and constrained, coming at the cost of an increased surveillance and commodification of intimate relations (Butt et al., 2016). For platform urbanism, 'participation' is not primarily about posting content on the Internet, but about a much broader scope of pervasive and mundane practices of everyday interactions, such that "the very nature of urban experience.... becomes a site for platform intermediation" (Barns, 2019, p. 8). Getting around the city can in this sense be a kind of platform participation (van der Graaf \& Ballon, 2019). In this view, a traveler setting her own origin and destination on Uber is creating a program on the Uber platform, a particular extension of the platform constrained but not determined by Uber. This section takes Lyft's user interface as an indication of the kind of participant this platform envisions and encourages, namely one who is a passive, individualistic consumer of a service.

In North America, Lyft is the second-largest ridehailing platform, with fewer rides in fewer places than its rival Uber, but is nonetheless a dominant player in Seattle and most metropolitan areas. Like Uber, Lyft has promised city officials that, despite mounting evidence to the contrary, ride hailing platforms can reduce con- gestion and emissions in major cities. Central to this promise is the use of pooled rides, by which passengers unknown to each other who have nearby origins and destinations ride together in the same vehicle for some portion of their trip. Through its algorithmic coordination of demand, Lyft promises to move more people in fewer vehicles. The company set a goal in 2019 of making "shared rides account for $50 \%$ of all trips on the Lyft platform by the end of 2020" (Lyft, 2019a). Yet as one state transportation secretary remarked at an industry conference, the ride pooling algorithms are easy, but "it is actually behavior and culture that is the part of this that we are really having a hard time" influencing (Pollack, 2019). That passenger behavior-choosing the pool option within the app interface, sometimes walking a few blocks to a designated pickup location, sharing a back seat with a stranger, and making detours for additional stops - competes with a kind of participation that is narrowly tailored to the individual passenger's current needs.

The app interface illustrates this personalized focus. Upon opening, the Lyft app uses the passenger's current location as a default pickup point, then asks "Where are you going?" and offers a personalized list of destinations. Once the origin and destination have been identified, the app shows a map highlighting the expected route, as well as a choice of ride options, including pooled options, which include estimated costs and arrival times (Figure 1). Throughout the booking and travel process, the app provides instructions and images that are specific to the rider's particular journey-her origin, destina-
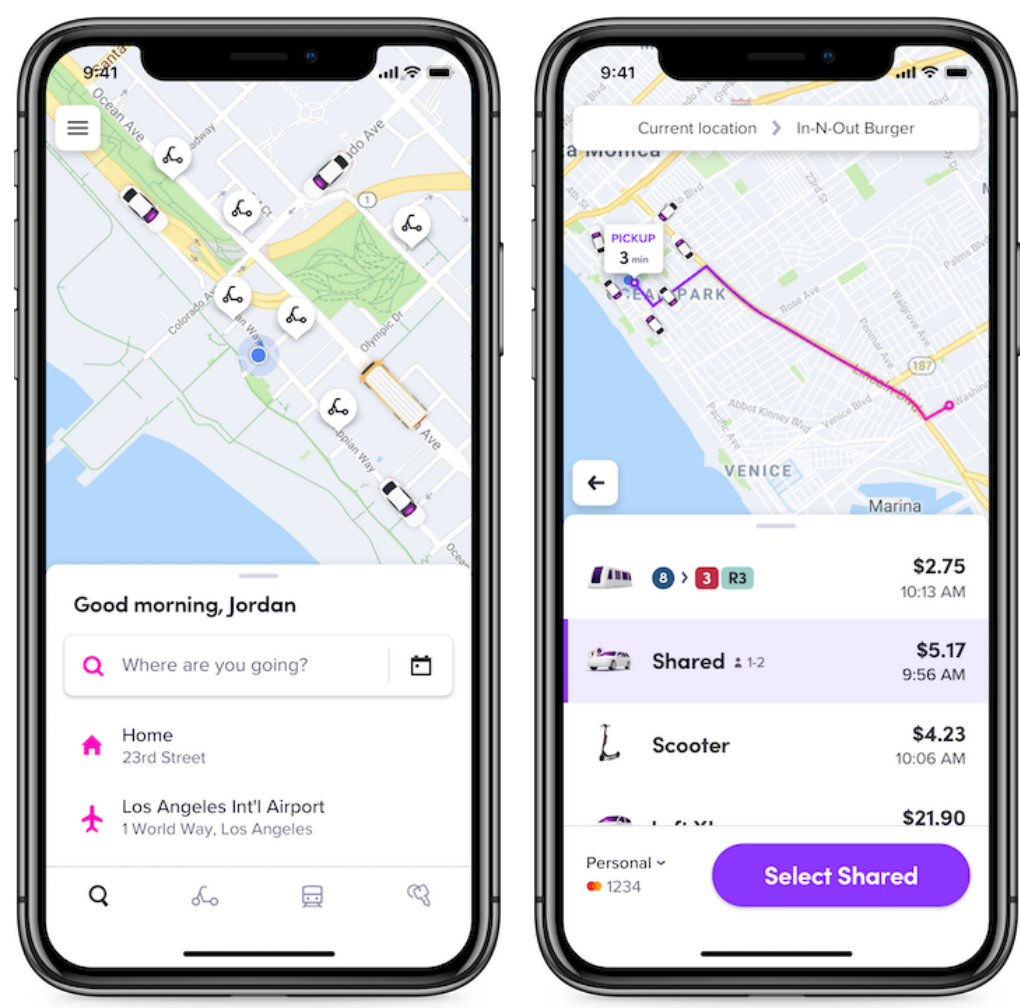

Figure 1. Screenshots from the user interface while booking a trip in the Lyft app. Source: Lyft (2019b). 
tion, route, and vehicle-but little surrounding social or environmental context. Features like pre-populated destinations, automatic payment, and real-time arrival estimates, and door-to-door service are designed to minimize the effort a traveler must make to move around town on the Lyft platform.

The pool option is easy to select from available ride options in the app interface, and Lyft even says it has modified its interface to encourage sharing (Lyft, 2019a). The estimated travel times, however, are typically both longer and less precise. One finding of interviews with the users of ride-hailing apps in Seattle was that the cost advantage of pooled rides was often outweighed by their uncertainty. One subject called it a "gamble," and said he avoids pools if he is in a hurry. Another said he worried about sharing a ride with drunk or unruly passengers. These riders wanted to know when exactly they would arrive, but also who they would need to sit with to get there. The individual ride option, still the default choice in the app interface, delivers an experience that is more predictable and personalized.

In the Lyft interface, and in its use by a particular traveler, we find a site of tension between Lyft's stated corporate goal of increasing shared rides and its prioritization of rider convenience. This illustrates both the power and limitations of the platform architecture. As long as the Lyft app presents options, the agency of its users will preclude Lyft from fully specifying all its travel activity. This agency is a reminder that digital systems do not exert control universally (Rose, 2017), and platforms, as participatory systems, are inherently indeterminate (Leszczynski, 2019a). At the same time, we can see how the app design is indeed an active presence in the traveler's decision-making. Lyft's interface allows comparison of the time and monetary costs to the individual user, but makes no mention of emissions or congestion, the metrics by which the benefits of carpooling accrue at the city scale. The system's accountability is based largely on the ratings riders and drivers give each other, but there is no ability for actors external to the transaction to evaluate, say, whether a driver performed an unsafe maneuver or a rider blocked traffic for the sake of an easier drop-off. While we could imagine an interface that actively nudges users towards more socially aware decision-making, Butt et al. (2016, p. 737) suggest that the individualistic nature of platform participation might be inherent to the form, which "focuses on individual contributions to a social network" with "instrumental" goals, rather than envisioning a more collective social engagement. To participate in the platform is to exercise an expanded agency of mobility, but only within the confines of a structure that presupposes a certain set of individual goals and priorities.

\subsection{Digitality: The Limits of Algorithmic Conflict Resolution}

The efficiency and reach of platforms as digital technologies is a result of their collection and manipulation of data, and therefore requires "a radical expansion in the forms of social interaction and transaction that can be rendered as data" (Amoore \& Piotukh, 2015, p. 345, emphasis in the original). Yet the reach of this digitization of everyday life is not unlimited. This section uses an example at the leading edge of digitization efforts, one app's automated parking-enforcement feature, to illustrate how platforms struggle to manage relations that are not easily monitored and quantified, even when they can automatically resolve more legible conflicts.

The city of Seattle's bike share vendor permit requirements document describes concern with the locations of shared bicycles at two scales. First, the city wants the bicycles to be available in neighborhoods across the city, and not only in the denser or richer neighborhoods likely to be most lucrative to vendors. The city permit therefore states that "the vendor shall distribute $10 \%$ or more of its deployed fleet in designated equity focus areas" (Seattle Department of Transportation, 2018, p. 50), neighborhoods that the Seattle Department of Transportation has identified for priority service (see Figure 2). Riders are allowed to complete their trips in any city neighborhood, but vendors have a responsibility to ensure adequate coverage at the beginning of each day, if necessary by redistributing bicycles. At a smaller scale, the city is also concerned with the location of parked bicycles within the public right-of-way. Free-floating bicycles do not have dedicated parking infrastructure, and so a rider can

\section{Map of Designated Areas:}

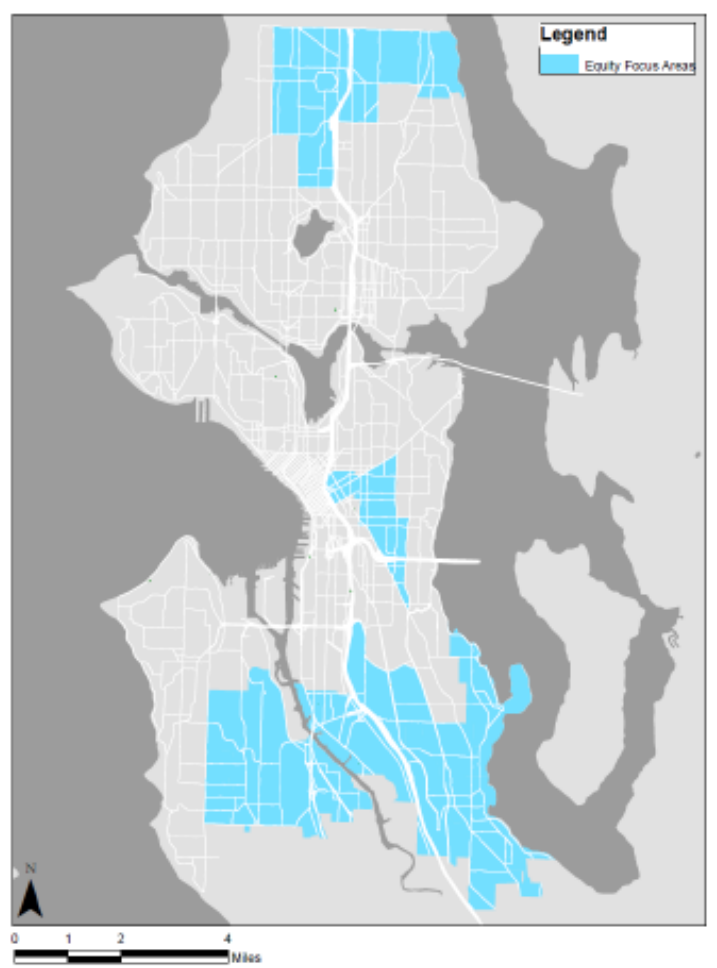

Figure 2. Map highlighting 'Equity focus areas' in which vendors must distribute $10 \%$ of their fleet. Source: Seattle Department of Transportation (2018). 
lock and leave a bicycle anywhere upon completing a trip. To avoid bicycles blocking sidewalks, doorways, and road traffic, the city has specified where in the right-of-way bike parking is permitted (see Figure 3 ). In this function, the city regulation seeks to protect the interests of those who are not users of bike share but who nonetheless have an indirect stake in its operation. Although the rider is responsible for proper parking, the city holds the vendor accountable for parking violations.

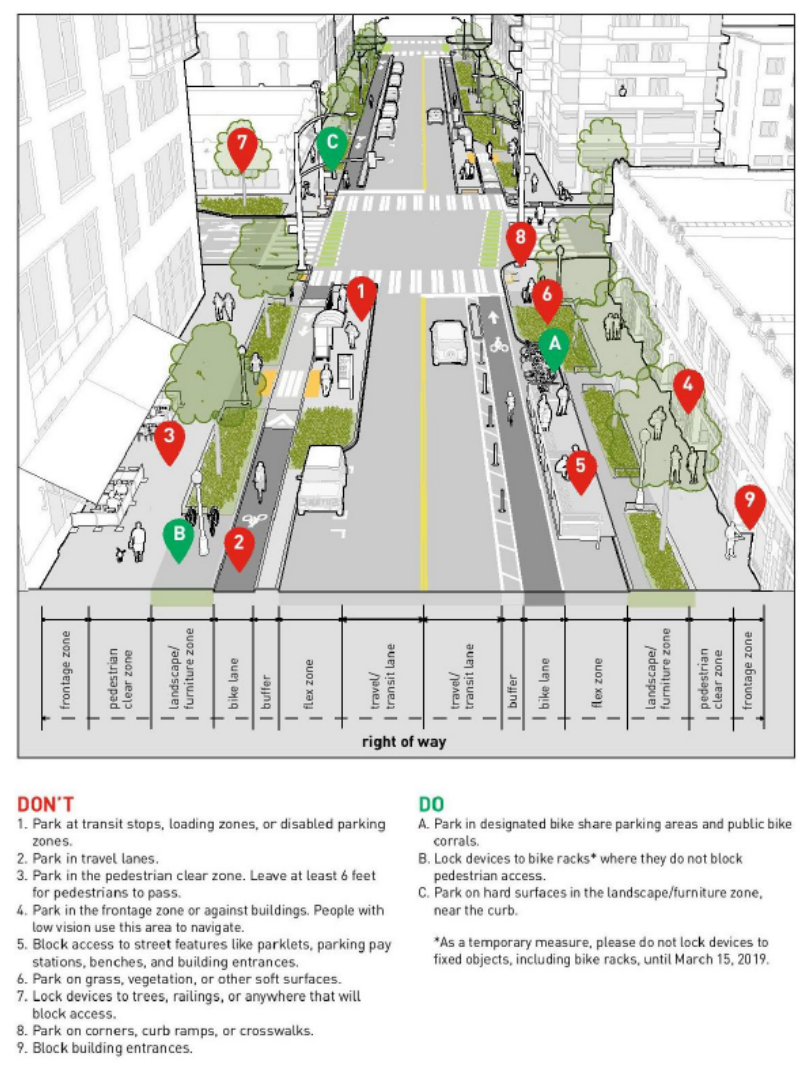

Figure 3. A diagram of a right-of-way showing where shared bikes should and should not be parked. Source: Seattle Department of Transportation (2018).

Digital technologies are involved in monitoring parking at both scales, but in very different ways. Each bicycle is equipped with a GPS receiver and periodically reports location data to the city using MDS. Seattle requires location accuracy to four decimal places in decimal degrees, approximately 10 meters. While some vendors provide more precise figures, reported location from these GPS units is generally unreliable beyond a few meters. For matching locations to neighborhoods, this spatial resolution is more than adequate. Given a dataset with the latitude and longitude of all parked bicycles at a given point in time, a city transportation official can easily calculate the number within the defined neighborhoods. Similarly, vendors can monitor a bicycle's location during a trip and notify the rider using a phone alert when they travel in or out of a geofenced no-parking zone (see Figure 4). A rider can also be automatically prevented from ending a trip in an unauthorized zone.
This location data is less helpful, however, for monitoring correct parking at the scale of the sidewalk. GPS cannot accurately differentiate between a bicycle parked incorrectly in the center of sidewalk and one parked properly one meter away, nor can it indicate the orientation of the bicycle-parallel to the sidewalk, perpendicular, or prone. Even with more accurate location data, Seattle would need to compare this against geographic data describing the right-of-way in great detail, including all street furniture, vegetation, building frontages, and entrances. Such high-resolution data is not available.

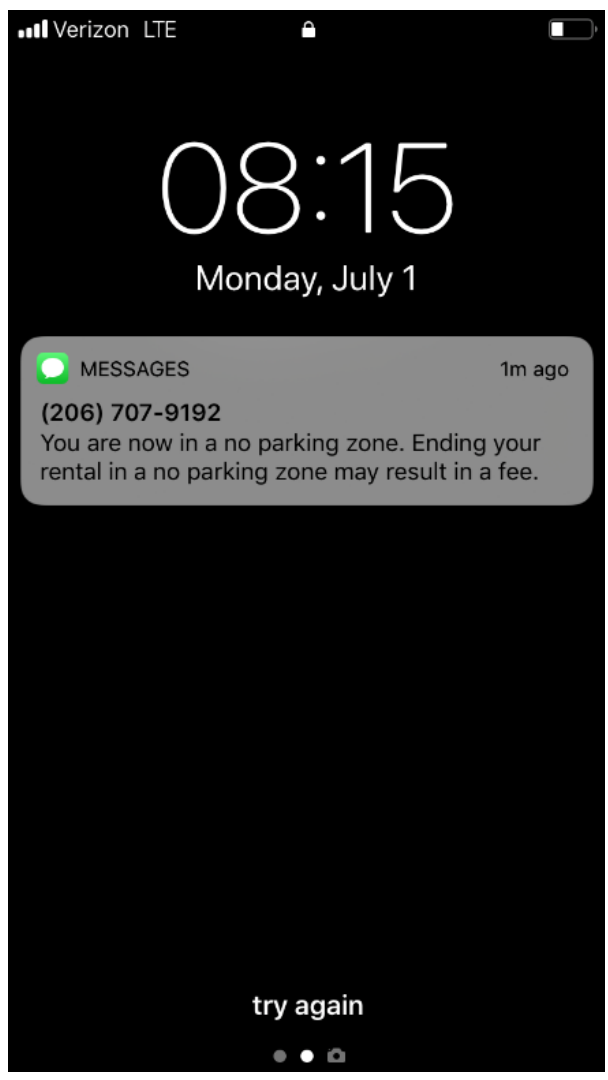

Figure 4. An SMS notification to a bike share rider upon entering a geofenced no-parking zone. Source: Author.

Parking education, monitoring, and enforcement is therefore largely managed without direct digital intervention. Signage on the bicycles themselves, graphics in the app, and instructional materials from both the Seattle Department of Transportation and the vendors instruct riders about proper parking, and the Seattle Department of Transportation conducts routine street audits of parking. However, one vendor, Lime, has suggested a path to automate parking enforcement. Upon completion of a trip, the Lime app asks the rider to take a photo of the parked vehicle. Separately, an in-app feature called Parked or Not (Figure 5) invites users to view photos of parked scooters, then indicate if they are parked correctly or not. Although Seattle does not currently permit scooters, cities that do apply similar restrictions on parking. In announcing the feature on its blog, Lime called it a "fun" way for "engaged riders to take 


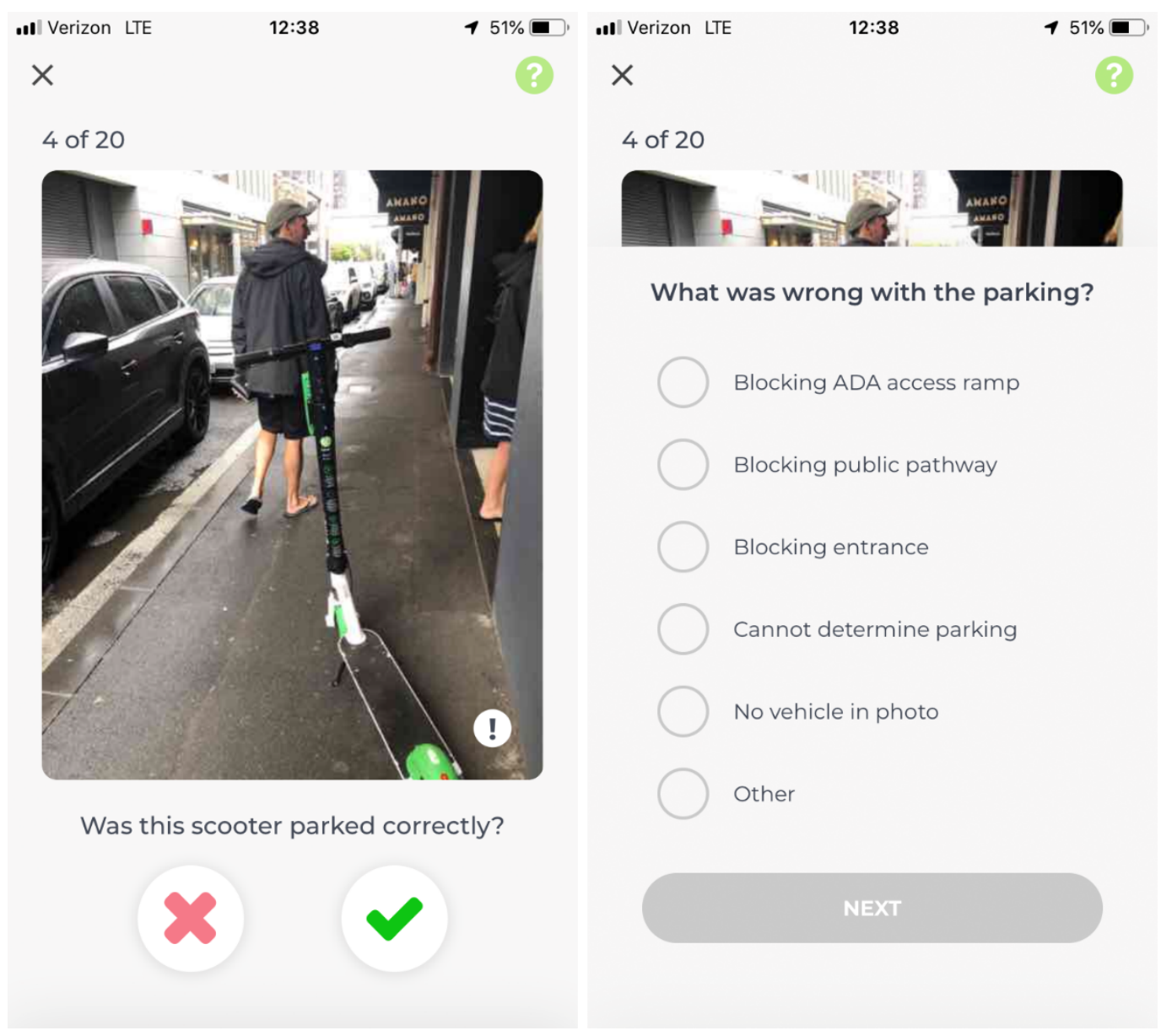

Figure 5. Screenshots of Lime's Parked or Not feature. Source: Author.

an active role in educating" other riders (Lime, 2018a). Less obvious to the user is that it is also a means of creating a scalable digital enforcement tool. The Parked or Not lead explained that "the next step is to develop statistical models that help us identify positive and negative behavior" (Lime, 2018a), and Lime, in its app for a Seattle permit, mentions its work "building out and implementing machine learning techniques to create an automated system that can verify rider's parking jobs" (Lime, 2018b). The apparent purpose of Parked or Not, then, is to use the human identification of images of correct and incorrect parking to create a training dataset that teaches an artificial intelligence to do the same automatically and at scale.

The details of the development and deployment of such systems are not publicly available, and the Parked or Not feature is no longer available on Lime's app. Still, a closer look at the possible mechanisms of this feature can help to illustrate the limitations of digital management of parking conflicts. First, the tool is of course not entirely digital, relying on hidden labor (Irani, 2015) whose value accumulates to the platform owners (Srnicek, 2017). Beyond these economic concerns, one problem with the system is its assumption that proper parking in a dynamic, three-dimensional urban context can be accurately identified from a single image.
The standardized approach also elides any local regulatory differences, since users are asked to evaluate parking without knowing anything about the nuances of parking guidance in the jurisdiction of the photo.

Indeed, the question of what constitutes 'correct' parking is largely subjective. Despite the specificity of Seattle's parking restrictions, they leave room for reasonable disagreement about whether a bike accords with the regulations, or whether those restrictions are actually appropriate for a given situation. Unobtrusive parking might be less of a concern on a quieter neighborhood street than on a high-traffic downtown sidewalk, for example. The ways that we occupy shared public spaces are inherently relational, requiring continual negotiations large and small among inhabitants whose goals sometimes collide. Lime's automated parking monitoring would presumably enforce a de facto parking standard blind to this social context. Indeed, the app effectively overlooks the very people who might be best situated evaluate proper parking. In mediating relationships among Lime, the Lime user, and the city regulator, the app excludes the external community of those who are directly affected by its use of public space. These interests are represented in the platform only indirectly through the city's regulations, and the platform's community is implied to be the actual users of the bikes and scooters. 
At least two differences can help explain the gap between the fairly straightforward digital monitoring of neighborhood distribution and the more complex automation of parking enforcement within the right-ofway. One is scale. The limited resolution of both bicycle location data and city geographic data means that the identification of a bicycle as either inside or outside of a desired zone is far more reliable at the scale of the neighborhood than at that of a human body on a sidewalk. A second issue is the difference between quantifiable targets and goals with a more qualitative, subjective character. In contrast to interpreting appropriate parking, calculating the percentage of bicycles available in defined neighborhoods is a fairly objective matter of locating and counting. The latter is more readily quantified and digitized, while the former can be digitized only clumsily, as Parked or Not illustrates.

\section{Conclusion}

Digital platforms are political in the ways they monetize participation and accumulate value (Srnicek, 2017), in their automated reproduction and acceleration of preexisting relations of domination (Noble, 2018), and in their mediation of everyday discourse and information exchange (Gillespie, 2018). Studies of technology have long emphasized that a given technology is a product not only of those who directly create it, but also of those who exercise their own agency in using it in particular ways to meet their own needs (Kline \& Pinch, 1996). However, as platforms further blur the distinction between production and use, these technologies become participatory in new ways. This demands a greater attention to the ways that they not only reflect and shape social values and relations, as science and technology studies has long argued of technology, but also how the platform becomes a site of value formation and relation building in itself. While such a framing is well established in studies of online social media, platform urbanism has more recently suggested a way to understand the digital organization of urban space as well. The examples of urban mobility technologies presented here have focused on three characteristics of the platform-its centralized architecture, its user participation, and its digitality-to argue that these constitute sites in which social relations are both enacted and ordered. These digital platform politics play out not just in code, but in everyday urban spaces, where they are made apparent in trip visibility, transportation availability, and the negotiations of shared public space. Through these examples, this article has pointed to a conceptualization of platform politics that connects the platform's technical organization and the means by which actors engage with one another in urban space.

The data specification, interface, and algorithmic tool presented here have each illustrated the simultaneous openness of platform participation and the confines of platform architectures. As infrastructures, they are easi- ly overlooked regulators of everyday behavior, while as forums of participation, they are relational and indeterminate. GBFS is an open-source specification with accessible contributor roles and a transparent development process. As a standard, however, it overrides local variations, limiting the ability of cities, or indeed travelers, to control their own data. On the Lyft platform, riders can move through the city in ways specific to their own needs, but this practice is constrained by an interface that presupposes an individualistic transaction. GPS monitoring of shared bikes is a way of ordering the messiness of participation on free-floating bike share platforms. This architectural control is limited, however, to practices that can be easily digitized. In the end, the platform frustrates any simplistic reading of its politics as inherently liberatory or oppressive. Yet as digital technologies "scale beyond the chambers of city halls and on to the personal networked devices of (nearly) every urban denizen" (Leszczynski, 2019a, p. 5) and as platforms become "urbanized" (Barns, 2019), the nuanced political arrangements attending the configurations of these digital platforms demand our careful consideration. With such a perspective, we can begin to see participation in the city as, in part, participation in its digital infrastructures.

\section{Acknowledgments}

An early version of this article was presented in October 2019, at the Annual Conference of the Association of Collegiate Schools of Planning, in Greenville, South Carolina. Thanks to the two anonymous reviewers of this article for their very helpful feedback and suggestions.

\section{Conflict of Interests}

The author declares no conflict of interests.

\section{References}

Amoore, L., \& Piotukh, V. (2015). Life beyond big data: Governing with little analytics. Economy and Society, 44(3), 341-366. https://doi.org/10.1080/03085147. 2015.1043793

Ananny, M., \& Gillespie, T. (2016). Public platforms: Beyond the cycle of shocks and exceptions. Oxford: Oxford Internet Institute.

Andersson Schwarz, J. (2017). Platform logic: An interdisciplinary approach to the platform-based economy. Policy \& Internet, 9(4), 374-394. https://doi.org/ 10.1002/poi3.159

Ash, J., Kitchin, R., \& Leszczynski, A. (2018). Digital turn, digital geographies? Progress in Human Geography, 42(1), 25-43. https://doi.org/10.1177/ 0309132516664800

Barns, S. (2019). Negotiating the platform pivot: From participatory digital ecosystems to infrastructures of everyday life. Geography Compass, 13(9). https://doi. org/10.1111/gec3.12464 
Barns, S. (2020). Platform urbanism: Negotiating platform ecosystems in connected cities. Singapore: Springer.

Bijker, W. E., Hughes, T. P., \& Pinch, T. (1987). The social construction of technological systems: New directions in the sociology and history of technology. Cambridge, MA: MIT Press.

Bucher, T. (2013). Objects of intense feeling: The case of the Twitter API. Computational Culture. http://computationalculture.net/objects-of-intensefeeling-the-case-of-the-twitter-api

Busch, L. (2011). Standards: Recipes for reality. Cambridge, MA: MIT Press.

Butt, D., McQuire, S., \& Papastergiadis, N. (2016). Platforms and public participation. Continuum, 30(6), 734-743. https://doi.org/10.1080/10304312.2016. 1231777

Crawford, K. (2016). Can an algorithm be agonistic? Ten scenes from life in calculated publics. Science, Technology \& Human Values, 41(1), 77-92. https://doi. org/10.1177/0162243915589635

Ducheneaut, N. (2005). Socialization in an open source software community: A socio-technical analysis. Computer Supported Cooperative Work, 14(4), 323-368. https://doi.org/10.1007/s10606-005-9000-1

Elwood, S., \& Leszczynski, A. (2018). Feminist digital geographies. Gender, Place \& Culture, 25(5), 629-644. https://doi.org/10.1080/0966369X.2018. 1465396

Fields, D., Bissell, D., \& Macrorie, R. (2020). Platform methods: Studying platform urbanism outside the black box. Urban Geography, 41(3), 462-468. https://doi.org/10.1080/02723638.2020.1730642

Galloway, A. R. (2004). Protocol: How control exists after decentralization. Cambridge, MA: MIT Press.

Gillespie, T. (2010). The politics of 'platforms.' New Media \& Society, 12(3), 347-364. https://doi.org/ $10.1177 / 1461444809342738$

Gillespie, T. (2018). Custodians of the Internet: Platforms, content moderation, and the hidden decisions that shape social media. New Haven, CT: Yale University Press.

Graham, M. (2020). Regulate, replicate, and resist: The conjunctural geographies of platform urbanism. Urban Geography, 41(3), 453-457. https://doi.org/ 10.1080/02723638.2020.1717028

Graham, S. (2005). Software-sorted geographies. Progress in Human Geography, 29(5), 562-580. https://doi.org/10.1191/0309132505ph568oa

Graham, S., \& Marvin, S. (2001). Splintering urbanism: Networked infrastructures, technological mobilities and the urban condition. London and New York, NY: Routledge.

Gurran, N., \& Phibbs, P. (2017). When tourists move in: How should urban planners respond to Airbnb? Journal of the American Planning Association, 83(1), 80-92. https://doi.org/10.1080/01944363.2016. 1249011
Helmond, A. (2015). The platformization of the web: Making web data platform ready. Social Media + Society, 1(2), 1-11. https://doi.org/10.1177/205630511 5603080

Irani, L. (2015). The cultural work of microwork. New Media \& Society, 17(5), 720-739. https://doi.org/ $10.1177 / 1461444813511926$

Kelkar, S. (2018). Engineering a platform: The construction of interfaces, users, organizational roles, and the division of labor. New Media \& Society, 20(7), 2629-2646. https://doi.org/10.1177/ 1461444817728682

Kim, A. J., Brown, A., Nelson, M., Ehrenfeucht, R., Holman, N., Gurran, N., . . . Kresse, K. (2019). Planning and the so-called 'sharing' economy/can shared mobility deliver equity?/The sharing economy and the ongoing dilemma about how to plan for informality/Regulating platform economies in cities: Disrupting the disruption?/Regulatory combat? How the 'sharing economy' is disrupting planning practice/corporatised enforcement: Challenges of regulating AirBnB and other platform economies/Nurturing a generative sharing economy for local public goods and service provision. Planning Theory \& Practice, 20(2), 261-287. https://doi.org/ 10.1080/14649357.2019.1599612

Kitchin, R., \& Dodge, M. (2011). Code/space: Software and everyday life. Cambridge, MA: MIT Press.

Kline, R., \& Pinch, T. (1996). Users as agents of technological change: The social construction of the automobile in the rural United States. Technology and Culture, 37(4). https://doi.org/10.2307/3107097

Langley, P., \& Leyshon, A. (2017). Platform capitalism: The intermediation and capitalization of digital economic circulation. Finance and Society, 3(1), 11-31. https://doi.org/10.2218/finsoc.v3i1.1936

Leszczynski, A. (2019a). Glitchy vignettes of platform urbanism. Environment and Planning D: Society and Space. https://doi.org/10.1177/0263775819878721

Leszczynski, A. (2019b). Platform affects of geolocation. Geoforum, 107, 207-215. https://doi.org/10.1016/ j.geoforum.2019.05.011

Lime. (2018a, July 25). New parked or not feature lets riders rate proper scooter parking. Second Street. Retrieved from http://v1.li.me/second-street/ parked-or-not-feature-riders-rate-scooter-parking

Lime. (2018b, August 15). Lime: Seattle 2018/19 freefloating bike share program permit application. San Francisco, CA: Lime.

Lyft. (2019a, April 23). Lyft's new app creates positive change for passengers and cities. Lyft Blog. Retrieved from https://blog.lyft.com/posts/new-app

Lyft. (2019b, September 24). One app to unlock your city. Lyft Blog. Retrieved from https://blog.lyft.com/ posts/lyft-multimodal-app

Mackenzie, A. (2018). From API to Al: Platforms and their opacities. Information, Communication \& Society. https://doi.org/10.1080/1369118X.2018.1476569 
MacKenzie, D. A., \& Wajcman, J. (1985). The social shaping of technology: How the refrigerator got its hum. Philadelphia, PA: Open University Press.

McFarlane, C., \& Rutherford, J. (2008). Political infrastructures: Governing and experiencing the fabric of the city. International Journal of Urban and Regional Research, 32(2), 363-374. https://doi.org/10.1111/ j.1468-2427.2008.00792.x

Mouffe, C. (1999). Deliberative democracy or agonistic pluralism? Social Research, 66(3), 745-758.

Nafus, D. (2011). 'Patches don't have gender': What is not open in open source software. New Media \& Society, 14(4), 669-683. https://doi.org/10.1177/ 1461444811422887

Noble, S. U. (2018). Algorithms of oppression: How search engines reinforce racism. New York, NY: New York University Press.

North American Bikeshare Association. (2019a). GBFS developers' workshop. Presented at the North American Bikeshare Association Annual Conference, Indianapolis, IN, USA. Retrieved from https://docs. google.com/document/d/1TXf3U7gbrJrS_r2PmTrfbJ spNydAyd42xU3ctNgzNLM/edit?usp=sharing\&usp= embed_facebook

North American Bikeshare Association. (2019b). Proposal: Rotate or remove bike_id from free_bike_status to prevent trip reconstruction re-identification: Issue \#146. Github. Retrieved from https://github.com/ NABSA/gbfs/issues/146

North American Bikeshare Association. (2019c). Rotate bike_id on free_bike_status by morganherlocker: Pull request \#147. Github. Retrieved from https://github. com/NABSA/gbfs/pull/147

North American Bikeshare Association. (2020, July 10). General bikeshare feed specification. Github. Retrieved from https://github.com/NABSA/gbfs

Open Mobility Foundation. (2020, July 10). Mobility data specification. Github. Retrieved from https:// github.com/openmobilityfoundation/mobility-dataspecification

Plantin, J.-C. (2015). The politics of mapping platforms: Participatory radiation mapping after the Fukushima Daiichi disaster. Media, Culture \& Society, 37(6), 904-921. https://doi.org/10.1177/0163443715584102

Plantin, J.-C., Lagoze, C., Edwards, P. N., \& Sandvig, C. (2018). Infrastructure studies meet platform studies in the age of Google and Facebook. New Media \& Society, 20(1), 293-310. https://doi.org/10.1177/ 1461444816661553

Pollack, S. (2019). Climate change and multi-modal mobility solutions for a sustainable future. Paper presented at the Shared-Use Mobility Summit, Chicago, IL, USA.

Richardson, L. (2020). Coordinating the city: Platforms as flexible spatial arrangements. Urban Geography, 41(3), 458-461. https://doi.org/10.1080/02723638. 2020.1717027

Rodgers, S., \& Moore, S. (2018, October 23). Platform urbanism: An introduction. Mediapolis. Retrieved from https://www.mediapolisjournal.com/2018/10/ platform-urbanism-an-introduction/

Rose, G. (2017). Posthuman agency in the digitally mediated city: Exteriorization, individuation, reinvention. Annals of the American Association of Geographers, 107(4), 779-793. https://doi.org/10.1080/ 24694452.2016.1270195

Seattle Department of Transportation. (2018, August 8). Free-floating bike share program permit requirements for the 2018-2019 permit year. Seattle, WA: City of Seattle.

Seattle Department of Transportation. (2019, December 30). City of Seattle mobility data: Privacy and handling guidelines. Seattle, WA: City of Seattle.

Srnicek, N. (2017). Platform capitalism. Cambridge and Malden, MA: Polity.

Star, S. (1999). The ethnography of infrastructure. The American Behavioral Scientist, 43(3), 377-391.

Steinmacher, I., Graciotto Silva, M. A., Gerosa, M. A., \& Redmiles, D. F. (2015). A systematic literature review on the barriers faced by newcomers to open source software projects. Information and Software Technology, 59, 67-85. https://doi.org/10.1016/j.infsof. 2014.11.001

Thrift, N., \& French, S. (2002). The automatic production of space. Transactions of the Institute of British Geographers, 27(3), 309-335.

van der Graaf, S., \& Ballon, P. (2019). Navigating platform urbanism. Technological Forecasting and Social Change, 142, 364-372. https://doi.org/10.1016/ j.techfore.2018.07.027

van Dijck, J., Poell, T., \& de Waal, M. (2018). The platform society: Public values in a connective world. New York, NY: Oxford University Press.

von Krogh, G., Spaeth, S., \& Lakhani, K. R. (2003). Community, joining, and specialization in open source software innovation: A case study. Research Policy, 32(7), 1217-1241. https://doi.org/10.1016/S00487333(03)00050-7

Winner, L. (1980). Do artifacts have politics? Daedalus, 109(1), 121-136.

\section{About the Author}

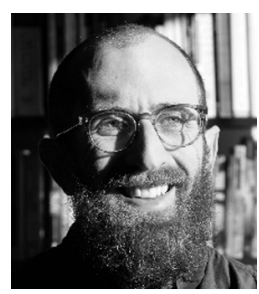

Peter T. Dunn is a Doctoral Candidate in the Interdisciplinary PhD Program in Urban Design \& Planning at the University of Washington. He is interested in the everyday use of digital technologies in the city, and his research examines dimensions of personal autonomy and public participation in smartphone apps for urban mobility. 